Effect of a metacognitive scaffolding on self-efficacy, metacognition, and achievement in e-learning environments

\author{
Nilson Valencia-Vallejo \\ Omar López-Vargas \\ Luis Sanabria-Rodríguez
}

Universidad Pedagógica Nacional, Bogotá-Colombia

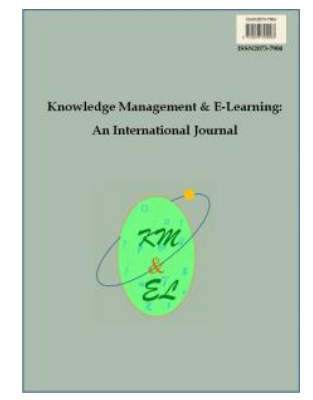

Knowledge Management \& E-Learning: An International Journal (KM\&EL) ISSN 2073-7904

Recommended citation:

Valencia-Vallejo, N., López-Vargas, O., \& Sanabria-Rodríguez, L. (2019). Effect of a metacognitive scaffolding on self-efficacy, metacognition, and achievement in e-learning environments. Knowledge Management \& ELearning, 11(1), 1-19. https://doi.org/10.34105/j.kmel.2019.11.001 


\title{
Effect of a metacognitive scaffolding on self-efficacy, metacognition, and achievement in e-learning environments
}

\author{
Nilson Valencia-Vallejo* \\ Facultad de Ciencia y Tecnología \\ Universidad Pedagógica Nacional, Bogotá-Colombia \\ E-mail: nvalencia@pedagogica.edu.co
}

\section{Omar López-Vargas}

Facultad de Ciencia y Tecnología

Universidad Pedagógica Nacional, Bogotá-Colombia

E-mail: olopezv@pedagogica.edu.co

\section{Luis Sanabria-Rodríguez}

Facultad de Ciencia y Tecnología

Universidad Pedagógica Nacional, Bogotá-Colombia

E-mail: lubsan@pedagogica.edu.co

*Corresponding author

\begin{abstract}
The object of the present research is to study the effects of a metacognitive scaffolding on metacognition, academic self-efficacy, and learning achievement in students with different cognitive styles in the Field Dependence-Independence (FDI) dimension when learning math content in an e-learning environment. Sixty-seven (67) students of higher education from a public university of Bogotá, Colombia participated in the study. The research has an experimental design with two groups and posttest. One group of students interacted with an e-learning environment, which includes within its structure a metacognitive scaffolding. The other group interacted with an environment without scaffolding. Findings show that the scaffolding promotes significant differences in metacognitive ability, academic self-efficacy, and learning achievement. Similarly, the data show that students with different cognitive styles achieve equivalent learning outcomes.
\end{abstract}

Keywords: Metacognitive scaffolding; Self-efficacy; Cognitive style; Learning achievement; e-Learning environments

Biographical notes: Dr. Nilson Valencia-Vallejo is an Associate Professor in the Faculty of Science and Technology, Universidad Pedagógica Nacional, Colombia. He earned a Bachelor's degree in Diseño Tecnológico, a Master's degree in Information Technologies Applied to Education and a Ph.D. in Education, all from the Universidad Pedagógica Nacional, Colombia. Professor-researcher and member of the Cognitek Research Group. He is interested in the theoretical aspects and the development of scaffolding in computational scenarios, the design of multimedia environments and uses of computers in education.

Dr. Omar López-Vargas is a tenured Professor in the Faculty of Science and 
Technology, Universidad Pedagógica Nacional, Colombia. He earned a Bachelor's degree in Mechanical Engineer from Universidad Nacional de Colombia and a Master's degree in Information Technologies Applied to Education and a Ph.D. in in Education, both from the Universidad Pedagógica Nacional, Colombia. Professor-researcher and member of the Cognitek Research Group. In the PhD program, offers seminars related to the design of multimedia environments for computer-mediated learning and the design of scaffoldings to aid learning in computer-based environments.

Dr. Luis Sanabria-Rodriguez is a tenured Professor in the Faculty of Science and Technology, Universidad Pedagógica Nacional. He earned a Bachelor's degree in Industrial Education from Universidad Pedagógica y Tecnológica de Colombia and a Master's degree in Information Technologies Applied to Education and a Ph.D. in in Education, both from the Universidad Pedagógica Nacional, Colombia. Cognitek Research Group Coordinator. In the PhD in Education Program, offers seminars on self-regulated learning, research methodologies in computer-based environments, and design of hypermedia environments for domain learning.

\section{Introduction}

During the last decades, Web-based learning environments have been frequently used in different levels and modalities of education to boost teaching-learning processes (Kazu \& Demirkol, 2014). The use of digital environments generates great expectations among the academic community since they are able to favor both students' learning autonomy and motivation, while respecting their individual differences (Chen \& Tseng, 2012). However, some studies reveal that not all students benefit equally in terms of learning achievement when learning in computational environments (Archer, 2003; Hsu \& Dwyer, 2004), which has been studied from three approaches: the first is related to the student's cognitive style; the second, to metacognitive abilities; and the third, to self-efficacy perception.

Regarding the first approach, namely, cognitive style, some authors state that the learning achievement reached by students when interacting with Web environments may be associated to individual differences. For example, in the field dependenceindependence -FDI- dimension, studies discuss these results (Alomyan, 2004; Chen \& Macredie, 2002; Handal \& Herrington, 2004; López-Vargas, Hederich-Martinez, \& Camargo-Uribe, 2011), evidencing that field dependent novices exhibit some difficulties in successfully interacting with Web environments; while their field independent classmates are more effective when interacting with computational environments (Archer, 2003; Hsu \& Dwyer, 2004; Palmquist \& Kim, 2000). In this sense, activities like browsing freely, controlling one's own learning process, and analyzing the information presented in the computational scenarios are tasks that can present some degree of complexity for field dependent novices (Alomyan, 2004; Chen \& Macredie, 2002).

With respect to the second approach and related to metacognitive abilities, it is possible to deduce from the studies that deficits in metacognitive abilities are related to a low learning achievement when a student interacts with digital environments since this type of scenarios require establishing concrete learning goals; planning activities to achieve the goal; and monitoring and regulating one's own learning process to change and/or adjust strategies, learning goals, and investing a greater effort to reach the desired 
achievement; among others (Graesser, McNamara, \& VanLehn, 2005; Kramarski \& Mizrachi, 2006).

Finally, studies referring to the third approach, academic self-efficacy, describe the existence of a positive correlation between personal efficacy perception and the learning achievement obtained by the student when interacting in computational environments (Moos \& Azevedo, 2008, 2009). It is pertinent to mention that students that trust their abilities are persistent and make more of an effort to achieve their learning goals (Moos \& Azevedo, 2008, 2009), In this same line of work, some research show that a possible association may exist between cognitive style in the FDI dimension and selfefficacy perception in the development of tasks in computer-based learning environments. In other words, field independent students render positive judgements regarding their abilities to complete academic tasks through the Web versus their field dependent classmates, who doubt their performance in Web-based environments (DeTure, 2004; López-Vargas et al., 2011; López-Vargas \& Triana-Vera, 2013; López-Vargas \& Valencia-Vallejo, 2012).

On the other hand, in the field of information technologies applied to education, studies show that the use of scaffolding may favor subjects' performance when they autonomously engage in learning tasks in e-learning environments (Greene, Moos, Azevedo, \& Winters, 2008; Kim \& Hannafin, 2011; Lehmann, Hähnlein, \& Ifenthaler, 2014; Zhang \& Quintana, 2012). In this research field, the use of metacognitive scaffolding, in Web-based scenarios, provides support so that the student is able to manage and regulate cognitive processes during their own learning process. In this sense, the subject is able to self-impose goals, objectively plan learning activities to achieve their goal, monitor what was planned, and self-evaluate the results obtained to change and/or adjust their planning as a function of the proposed goals (Molenaar, Boxtel, \& Sleegers, 2010; Quintana, Zhang, \& Krajcik, 2005; Zhang \& Quintana, 2012). In this order of ideas, the novice's metacognitive ability can be positively affected by the use of the scaffolding insofar as it could favor decision making regarding organization, planning, monitoring, and regulation of one's own learning process.

Now, with respect to metacognitive ability and cognitive style, some works show indications of a possible association between field independent students and the use of metacognitive abilities, hypothesis that derives from the stylistic characteristics of FI students, who are intrinsically oriented toward learning and are interested in achieving goals (López-Vargas et al., 2011; Huertas, López, \& Sanabria, 2017). Although the studies are inconclusive and there is no consensus among researchers, it is necessary to continue inquiring into these possible associations to understand and comprehend the behavior of novices with different cognitive styles interacting in Web-based learning environments, and thus, propose alternative solutions to favor a more equitable and flexible learning as a response to their individual differences. posited:

In accordance to the foregoing statements, the following research questions are

1. What is the effect of a metacognitive scaffolding on academic self-efficacy, metacognition, and learning achievement in students of higher education that learn mathematical content in an e-learning environment?

2. Do significant differences exist in metacognitive ability, academic self-efficacy, and level of learning achievement between students with different cognitive styles in the Field Dependence/Independence (FDI) dimension when learning mathematical content in an e-learning environment? 


\section{Literature review}

\subsection{Cognitive style in the FDI dimension and web-based learning environments}

One of the most studied dimensions of cognitive style and with a broad theoretical development and applied to the educational context is the FDI dimension proposed by Witkin and his colleagues since 1948 (López-Vargas \& Valencia-Vallejo, 2012). The FDI dimension describes individuals along a continuum, where the individuals that are located at one of its endpoints are denominated Field Independents (FI), and at the other endpoint, Field Dependents (FD). The former, FI, exhibit a tendency toward an analytical and independent type of processing of environmental factors; the latter, FD, on the contrary, show tendencies toward a global-type of processing and highly influenced by the environment (López-Vargas et al., 2011).

Some authors have shown interest in studying the characteristics and the behavior of students in the FDI dimension when interacting in computational scenarios (Alomyan, 2004; Handal \& Herrington, 2004; López-Vargas, Ibáñez-Ibáñez, \& Racines-Prada, 2017; Lu, Yu, \& Liu, 2003). Studies show that FI individuals can be identified for adopting a non-linear learning approach and, in this sense, they prefer to browse freely without following pre-defined paths. Similarly, they can organize and structure the information presented to them and they possess high capabilities of taking control of their own learning process. On the other hand, FD novices, when on the Web, prefer guided browsing, require clear location and orientation signals, and search for external sources of support to guide them during their learning process. In this sense, they prefer to learn in scenarios where the control of learning is exercised by the computational program (Alomyan, 2004; Handal \& Herrington, 2004).

The characteristics of FI and FD individuals are related to learning achievement differences obtained when interacting in Web environments. It is evident that FI students exhibit better performances since they possess abilities to identify the relevant information, they take an active approach to their learning, and get less distracted; therefore, their performance is more efficient. Instead, FD find it difficult to identify useful information, it takes them longer to locate key concepts, and are easily disoriented during information searches. These characteristics probably impede them from performing effectively in Web scenarios (Alomyan, 2004; Handal \& Herrington, 2004).

From previous research on individual Web-based learning differences, it is possible to establish that FI individuals tend to surpass FD in different tasks, situation with direct implications on the learning process, individual academic achievement, and the way of accessing knowledge in Web scenarios (Angeli, Valanides, \& Kirschner, 2009; Archer, 2003; Palmquist \& Kim, 2000; Shih \& Gamon, 2002). In this sense, the challenge exists of designing computational scenarios that allow reducing individual learning differences between students so that it can be more equitable and flexible.

\subsection{Metacognition and cognitive style in computational scenarios}

The term metacognition was coined by Flavell in the 1970s and he defines it as the knowledge that one person has of their own cognitive process and the control they exercise on it (Flavell, 1976). Subsequently, Brown (1987) indicated that metacognition implies the regulation of the cognition where the novices control the learning processes. This component allows the student to reflect on task development, make judgements on 
the results obtained, and modify the aspects they consider necessary to improve their performance.

In this line of work, Nelson and Narens (1990) formulated an interpretative model of metacognitive functioning, which centers on two processes: monitoring and control. Monitoring allows the individual to identify and characterize their cognitive processes; while control allows them to take actions to improve the performance of cognitive functions considering the information provided by the monitoring. In this sense, monitoring includes processes such as task identification, verification and evaluation of the progress made, and prediction of expected results. On the other hand, the control process refers to actions like resource assignment, adjustment of the strategies used, activity prioritization, and specification of the steps to complete the task and the effort to complete it (Schraw \& Moshman, 1995; Schmidt \& Ford, 2003). For example, a student that has developed these abilities recognizes what, how, and when to use their knowledge; plans and organizes their learning strategies; monitors and evaluates the development of their activities; and controls their behavior as a function of adjusting and/or changing those conditions that are not a function of their learning (Huertas et al., 2017).

The metacognitive model has been the object of study in the field of information technologies applied to education, as a pedagogic and/or didactic strategy to favor students' learning achievement when interacting with computational scenarios (Huertas et al., 2017; Kramarski \& Gutman, 2006; Lajoie, 2005; McNeill, Lizotte, Krajcik, \& Marx, 2006; Zhang \& Quintana, 2012). In this line of work, findings have indicated that students with high metacognitive abilities exhibit better attitudes and learning achievements (Azevedo, 2005; Moos \& Azevedo, 2008). Pedagogic strategies have been designed through metacognitive scaffolding that can effectively support novices with metacognitive ability deficits to favor their learning achievement (Kim \& Hannafin, 2011; Kramarski \& Gutman, 2006; Molenaar, van Boxtel, \& Sleegers, 2010).

The concept of scaffolding originated from that posited in the Zone of Proximal Development (ZPD) by Vygotsky (1978). It refers to the social support provided to the student during the completion of a learning task when solving a problem or to reach a goal that was initially beyond their reach. In this sense, scaffolding are seen as a pedagogic support to the teaching process to improve the results of learning (Wood, Bruner, \& Ross, 1976). In the development of this theory, researchers explore the potential of incorporating different types of computational scaffolding during learning mediated by Information and Communications Technologies (ICT) to approach the difficulties students' face when managing and regulating their cognition during the learning process (Alexander, Bresciani, \& Eppler, 2015; Hederich-Martinez, LópezVargas, \& Camargo-Uribe, 2016; Law, Ge, \& Eseryel, 2011; Moos \& Azevedo, 2008).

The concept of scaffolding has been applied in the design of computational scenarios and is a growing source of research that has been developing in recent decades. Consequently, hypermedia environments and Web-based learning environments are being implemented that favor learning and self-regulation processes (Azevedo \& Hadwin, 2005; Zhang \& Quintana, 2012). Studies based on student's cognitive styles have also been developed (Hederich-Martinez et al., 2016; Huertas et al., 2017). In this field of work, some researchers seek to identify possible associations between students' metacognition and cognitive styles through the development and implementation of metacognitive scaffolding in computational scenarios. These scenarios are oriented toward favoring learning achievement and the development of metacognitive abilities as a response to subjects' individual differences (Hederich-Martinez et al., 2016; Hsu, Frederick, \& Chung, 1994; Huertas et al., 2017). 
To this respect, Huertas et al. (2017) studied the influence a metacognitive scaffolding incorporated in a b-learning environment has on learning chemistry content in high school students with different cognitive styles. Findings revealed that both FD and FI students benefited from the presence of the metacognitive scaffolding, which fostered the development of metacognitive abilities. Specifically, planning, organization, monitoring, and evaluation abilities during learning task completion. However, FI students obtained better learning achievements than their FD classmates. In this sense, it is evidenced that the scaffolding did not achieve an equitable and flexible learning in novices with different cognitive styles. Differences in learning achievements remain.

In another study, Hederich-Martinez et al. (2016) worked with postgraduate students in an e-learning environment, which incorporated a metacognitive scaffolding. They found that FI students exhibited better academic achievements than their FD classmates. In a previous study, Hsu, Frederick, and Chung (1994) observed the effect of a hypermedia environment that incorporated tools to support metacognition on academic performance in students of higher education with different cognitive styles in the FDI dimension. The findings indicated that no differences exist in learning achievements between FI and FD novices.

Although the studies are inconclusive, the use of pedagogic strategies through metacognitive scaffolding, in computational scenarios, favors learning achievements of students with different cognitive styles. Therefore, the need exists to continue researching the necessary characteristics for the design and implementation of metacognitive scaffolding that favor learning achievement in a more equitable and flexible manner and to a certain extent, get FD students to obtain better performances when interacting in computational environments.

\subsection{Academic self-efficacy and cognitive style}

Academic self-efficacy is conceived as the judgments students' make about their own abilities to organize and execute educational activities (Zimmerman, 1995). Some studies focus on examining what the influence of academic self-efficacy is and how it operates during learning processes in diverse academic contexts and knowledge domains (Schunk, 1989; Schunk \& Zimmerman, 2007; Tsai, Chuang, Liang, \& Tsai, 2011; Usher \& Pajares, 2009; Valencia-Vallejo, López-Vargas, \& Sanabria-Rodriguez, 2016, 2018). In this sense, when students work on academic activities and perceive their academic progress, their motivation toward learning increases. Thus, students maintain a strong sense of selfefficacy, participate with greater disposition, strive and persist in their goals, and overcome the obstacles when they face a learning task.

Self-efficacy and cognitive style in the FDI dimension are object of study in the ICT context. A study conducted by López-Vargas et al. (2011) with high school students found correlations between cognitive style in the FDI dimension and self-efficacy perception. In a previous study, DeTure (2004) explored the associations between selfefficacy, cognitive style, and academic achievement of students of higher education that work in a Web-based distance education environment. The analyses revealed that FI students reported higher self-efficacy perceptions than FD students. However, in terms of academic achievement, no significant differences were reported.

Subsequently, López-Vargas and Valencia-Vallejo (2012) examined the effect of a self-regulating scaffolding in a hypermedia environment on self-efficacy, academic achievement, and cognitive style of high school students. The study revealed that the scaffolding favored FD students' self-efficacy perception and academic achievement. No 
significant differences in learning achievements were reported in the study. Subsequently, López-Vargas and Triana-Vera (2013) explored the effect of a self-efficacy module in a hypermedia environment on the learning achievements in primary students with different cognitive styles. The findings showed that FI novices exhibit higher levels of selfefficacy. In addition, no individual differences in learning achievements were reported. As it is possible to observe, the research findings are inconclusive. Therefore, there is a need to continue researching into the design of pedagogic and/or didactic strategies that favor a more equitable and flexible learning achievement between students with different cognitive styles.

Based on the research on the benefits of computational scaffolding, the present research analyzes the effect generated by the incorporation of a metacognitive scaffolding within the structure of an e-learning environment to learn mathematics. This pedagogic strategy could be useful in reducing the differences in learning achievements in students with different cognitive styles in the FDI dimension and, at the same time, it could support students' construction of better self-efficacy perceptions.

\section{Method}

\subsection{Design}

The research is of an experimental-type; in other words, subjects were randomly assigned to the workgroups. The study's independent variable is the e-learning environment with two values: one group that interacted with an e-learning environment containing a metacognitive scaffolding and another group that interacted with an e-learning environment without scaffolding. The study possesses an associated variable denominated cognitive style in the FDI dimension, with three values: field dependents, intermediates (INT), and independents. In this sense, the design for the analysis of the results can be considered a 2 x 3 factorial design. The dependent variables were metacognitive ability, academic self-efficacy, and learning achievement.

\subsection{Participants}

Sixty-seven (67) first semester students (13 women and 54 men) of the Bachelor's in Technological Design program from the Universidad Pedagógica Nacional of the city of Bogotá, Colombia participated in the study. Ages vary between 16 and 38 years $(\mathrm{M}=$ 20.72 years, $\mathrm{SD}=3.69$ ). All the participants are enrolled in first semester.

\subsection{Materials}

e-Learning environment. The e-learning environment designed specifically for this research was denominated "Introductory Course to Mathematics". The course is comprised of six study units in mathematics. The environment includes different formats to present the information, such as texts, graphs, infographics, and videos, among others. There are also diverse learning activities and links to other websites tending to complement the content if needed. The characteristics of the metacognitive scaffolding are described below.

Learning activation. This stage is comprised of two sub-stages. In the first one, the scaffolding presents a set of questions or metacognitive activators (Ease of learning- 
EOL), so that the student reflects on: How much do they know about the subject matter, how competent do they feel to learn, what is their perception of difficulty-ease to solve problems on the subject matter? In the second one, the novice takes an initial test of prior knowledge composed of three exercises with immediate feedback. These two activities seek to make the student more aware of their own knowledge and stimulate them to reflect on their abilities to undertake learning in a more realistic way; thus, preparing them for the next stage.

Goal formulation and learning planning. In the first place, the student formulates a learning goal considering a scale of: Basic (decontextualized operational problem solving), intermediate (contextualized problem solving with one variable), and advanced (contextualized problem solving with two or more variables). The set goal will subsequently act as a personal criterion to monitor learning.

In the second place, they plan the activities, setting the study time by choosing one of the options that adjusts to their learning pace ( 2 hours, 3 hours, 4 hours, 5 hours, or more hours; how many?). Subsequently, they choose the resources available in the elearning environment and the external resources they consider important to support their learning process (see Fig. 1). Once they complete the planning, the scaffolding presents the student with a summary of the planning and requests they adjust it according to the established learning goal, if they consider it pertinent. The chosen learning goal and the planning can be viewed by the student, who can modify them during the learning process, considering the control processes they perform throughout the module denominated "My Planning".

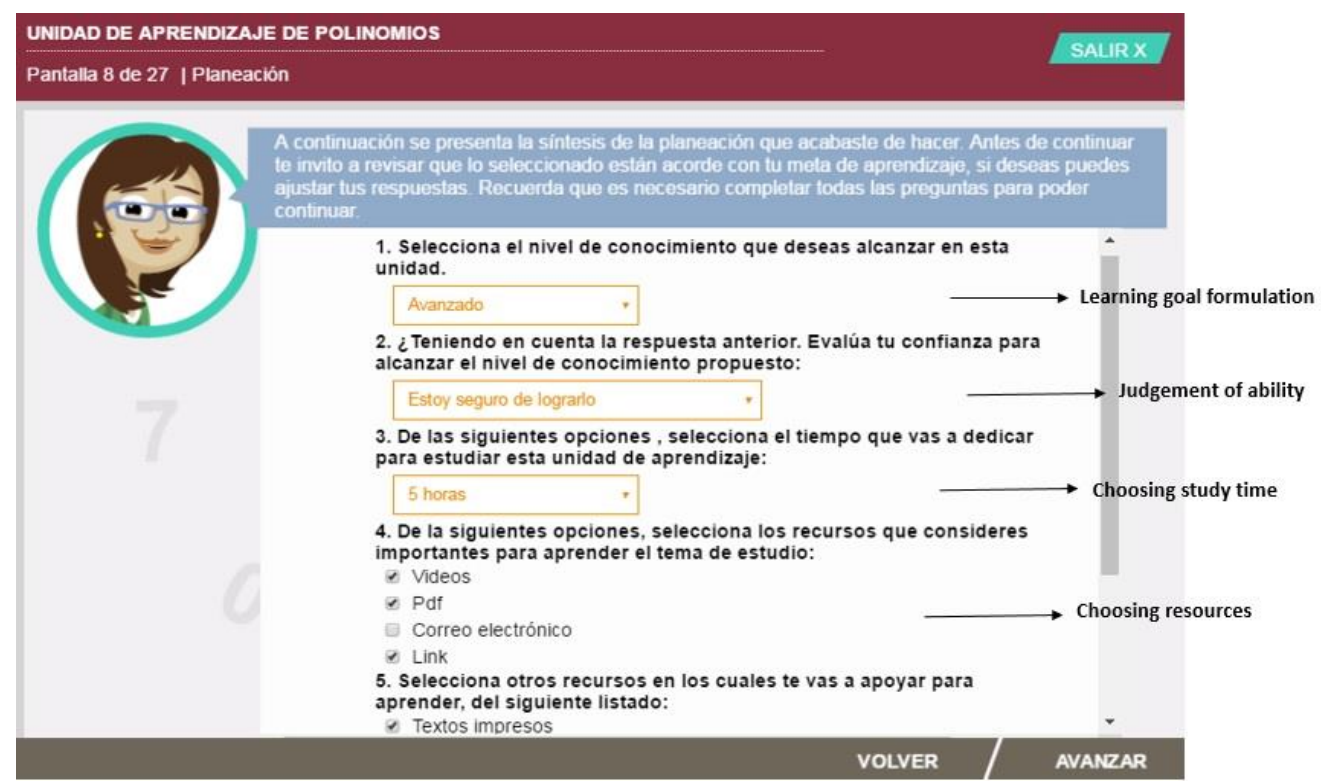

Fig. 1. Goal formulation and activity planning - Module "My Planning"

Acquisition stage - ongoing learning. During the development of this stage, the student interacts with the learning content and performs the monitoring process. In other words, they review if the completed learning process brings them closer to the set learning goal. Thus, they self-evaluate the actual state of their knowledge in relation to the desired state, while the scaffolding's objective is to induce them to perform metacognitive monitoring. As a complement to monitoring, the scaffolding uses screen 
messages as metacognitive activators (Judgments of learning - JOL) to stimulate the student to reflect on their own learning process. Example: Are they understanding the subject matter, do they think they should modify the initial planning, do they think that the planned time is sufficient to understand the subject, are they using the environment's resources to study the subject in-depth, what result would they obtain if they take a selfevaluation at this time?

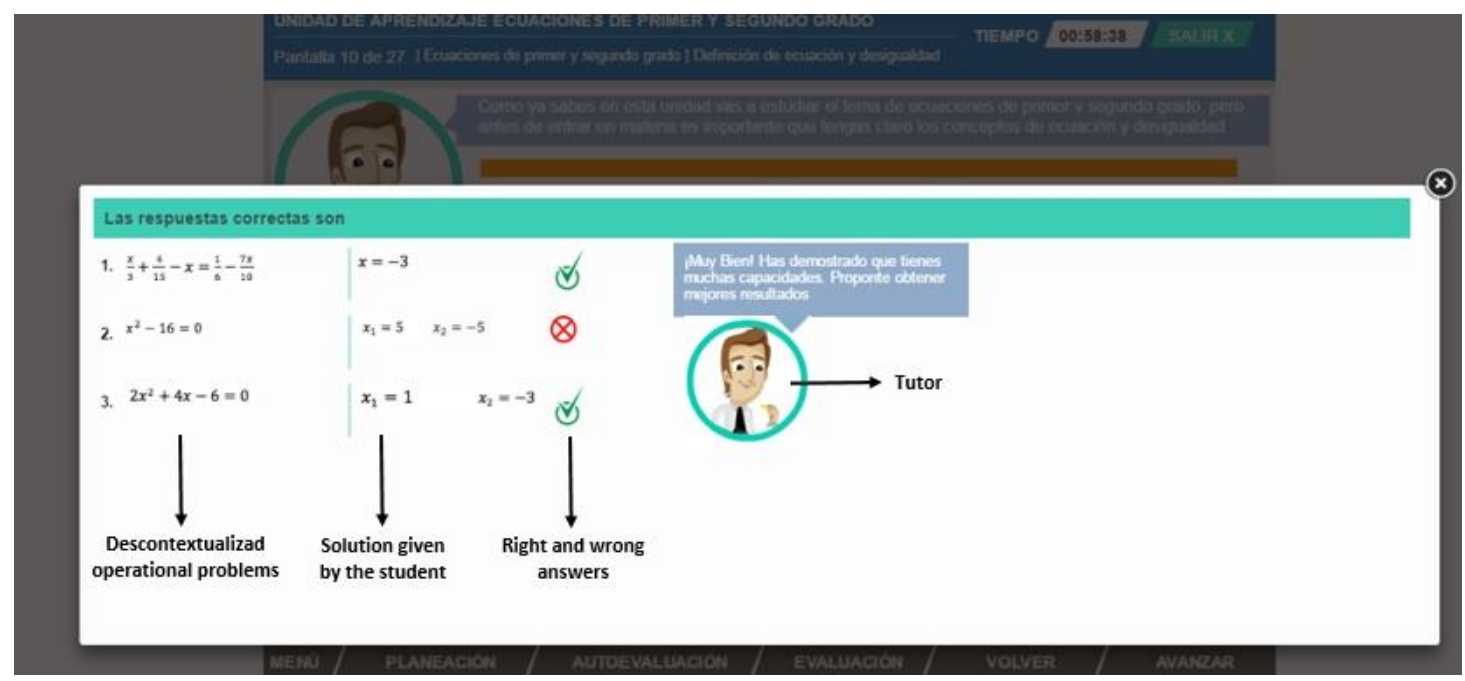

Fig. 2. Self-evaluation module

Similarly, to monitor the level of learning, the scaffolding includes a resource called "Self-evaluator", which is a self-evaluation module that presents exercises equivalent to that of the final evaluation (see Fig. 2), so that the student is aware of the achievements accomplished. According to the result, the novice can make the necessary adjustments if needed. In other words, they can review the content, modify the planning, or self-evaluate themselves as many times as they deem necessary. This process would correspond to the metacognitive control process. Finally, the student makes the decision to take the final evaluation of the content learned.

Ending. Through this stage, the scaffolding proposes to the student to perform a final reflection on the results obtained based on metacognitive activators (Feeling of knowing -FOK), such as: What is their perception on the level of domain of the subject matter, was the study time adequate for the results obtained, were the resources used adequate? These questions will likely allow the student to be more realistic in the following learning module (see Fig. 3). 


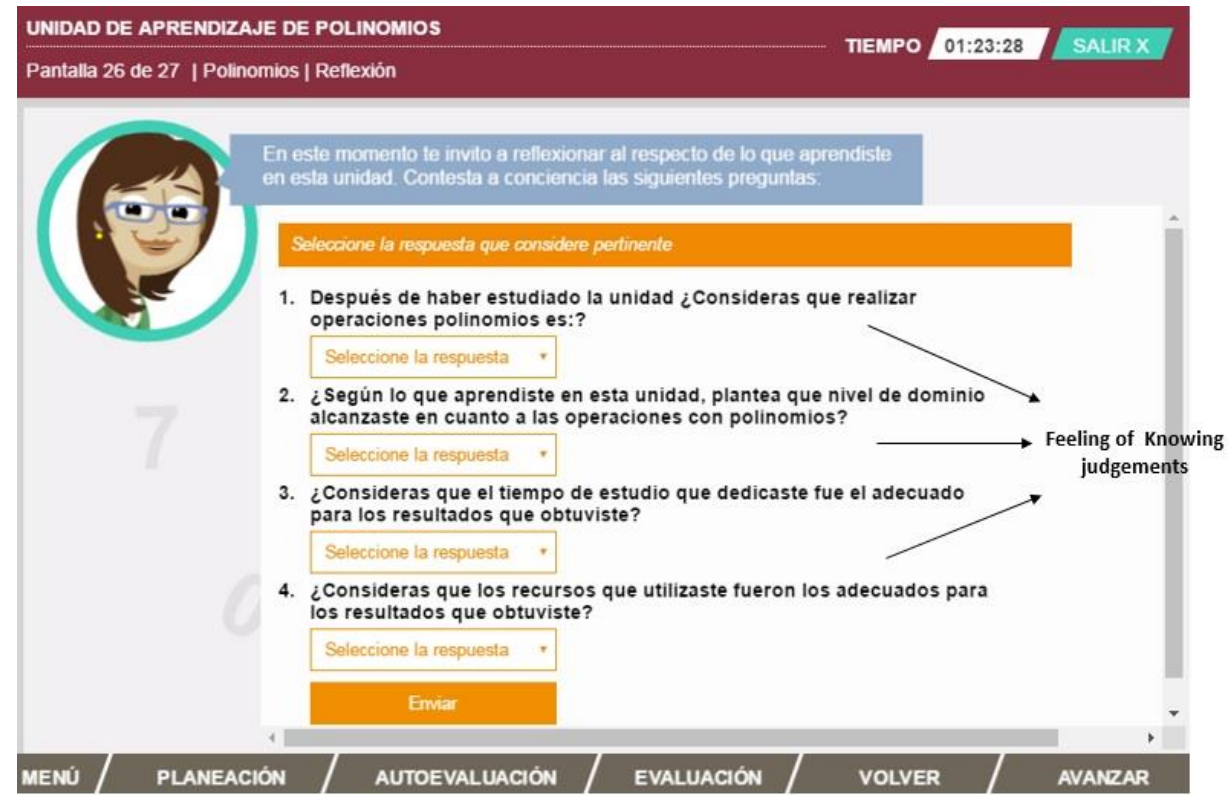

Fig. 3. Reflection on the results obtained

\subsection{Instruments}

Cognitive style test. To determine students' cognitive style, the Embedded Figures Test (EFT) is used (Sawa, 1966). Out of a maximum EFT score of 50, the minimum value was 10 points and the maximum value was 46 points. $(\mathrm{M}=28.18 ; \mathrm{SD}=7.785)$. Through terciles, three groups of students were identified, namely: (a) 24 field dependent students, (b) 20 intermediate novices, and (c) 23 field independent subjects. The instrument's internal consistency presented a Cronbach's alpha $=0.87$.

Learning achievement. Students answer six evaluations, one for each unit lesson. All the evaluations consist of five problems with multiple-choice answers. The evaluations are presented in the e-learning environment and the corresponding results were recorded in a database. The evaluations present a Cronbach's alpha $=0.785$.

Metacognitive ability sub-scales and self-efficacy of the MSLQ instrument. To determine students' perception of metacognitive ability and academic self-efficacy, the sub-scales corresponding to the Motivated Strategies for Learning Questionnaire (MSLQ) were used (Pintrich, Smith, García, \& McKeachie, 1991). The test is answered with a seven-point Likert scale $(1=$ No, never...; $7=$ Yes, always $)$. The instrument's internal consistency presents a Cronbach's alpha $=0.787$ for the sub-scale of metacognitive selfregulation and 0.882 for the sub-scale of academic self-efficacy.

\subsection{Procedure}

To conduct the study, authorization from the board of the Bachelor's in Technological Design of the Universidad Pedagógica Nacional of Bogotá, Colombia, requesting they allow first semester students to participate in the study was obtained. With the corresponding authorization, students were presented with the proposal and were 
requested to sign an informed consent to participate in the study. Subsequently, a group EFT was applied.

Afterwards, students were given an induction on the e-learning environment. Each participant was randomly assigned to one of the experimental conditions and were given a username and access to the platform. The experimental process had a duration of two months. One week later, after having completed the interaction stage with the e-learning environment, students were given the metacognitive self-regulation subscale and the academic self-efficacy subscale of the MSLQ instrument, which was managed through Google Drive.

\section{Results}

To process the data a Multivariate Analysis of Variance (MANOVA) was conducted. The study's dependent variables are: metacognitive ability, academic self-efficacy, and learning achievement. As main factors assumed: 1) the e-learning environment, with two values: with metacognitive scaffolding and without scaffolding; and 2) cognitive style with three values: field dependent, intermediate, and independent students.

In the first place, compliance with the assumptions of normality and homogeneity of the covariance matrixes for the dependent variables was verified. For metacognitive ability, the Shapiro-wilk normality test is verified, both for the experimental group $(\mathrm{W}=0.953, \mathrm{p}=0.168)$ and the control group $(\mathrm{W}=0.951, \mathrm{p}=0.131)$. Similarly, for academic self-efficacy, experimental group $(\mathrm{W}=0.968, \mathrm{p}=0.416)$ and control group $(\mathrm{W}=0.987$, $\mathrm{p}=0.943)$, as well as for the learning achievement, experimental group ( $\mathrm{W}=0.976$, $\mathrm{p}=0.647)$ and control group $(\mathrm{W}=0.991, \mathrm{p}=0994)$. Box's $\mathrm{M}$ homogeneity test ( $\mathrm{F}$ (30, $7646.261)=0.595, \mathrm{p}=0.961)$ was also verified. Once the assumptions are verified and complied, a MANOVA is performed. Tables 1, 2, and 3 present the summary of the descriptive statistics of the groups of students that worked in the e-learning environment with scaffolding and without scaffolding, considering cognitive style.

Table 1

Metacognitive ability results: Mean scores and standard deviations

\begin{tabular}{ccccc}
\hline e-Learning Environment & Cognitive Style & No. & M & SD \\
\hline With scaffolding & Field dependent & 12 & 5.20 & 0.49 \\
& Field intermediate & 9 & 4.95 & 0.63 \\
& Field independent & 12 & 5.34 & 0.41 \\
& Total & 33 & 5.18 & 0.51 \\
Without scaffolding & Field dependent & 12 & 4.80 & 0.74 \\
& Field intermediate & 11 & 4.83 & 0.56 \\
& Field independent & 11 & 4.66 & 0.64 \\
& Total & 34 & 4.76 & 0.64 \\
\hline
\end{tabular}

From the MANOVA, it is possible to evidence that no significant interaction exists between the e-learning environment's main factors, cognitive style with learning achievement $(\mathrm{F}(2,61)=1.328, \mathrm{p}=0.272, \eta 2=.042)$. Similarly, it is possible to establish that a significant main effect of the e-learning environment exists $(F(1,61)=7.569, p=$ $0.008, \eta 2=0.110$ ) on metacognitive ability in favor of the students that interacted with the version of the e-learning environment that included the metacognitive scaffolding. 
Students that worked with the scaffolding designed for the study reported better levels of metacognitive ability $(\mathrm{M}=5.18, \mathrm{SD}=0.51)$ compared to the students that did not use the scaffolding $(\mathrm{M}=4.76, \mathrm{SD}=0.64)$ (see Table 1) (see Fig. 4).
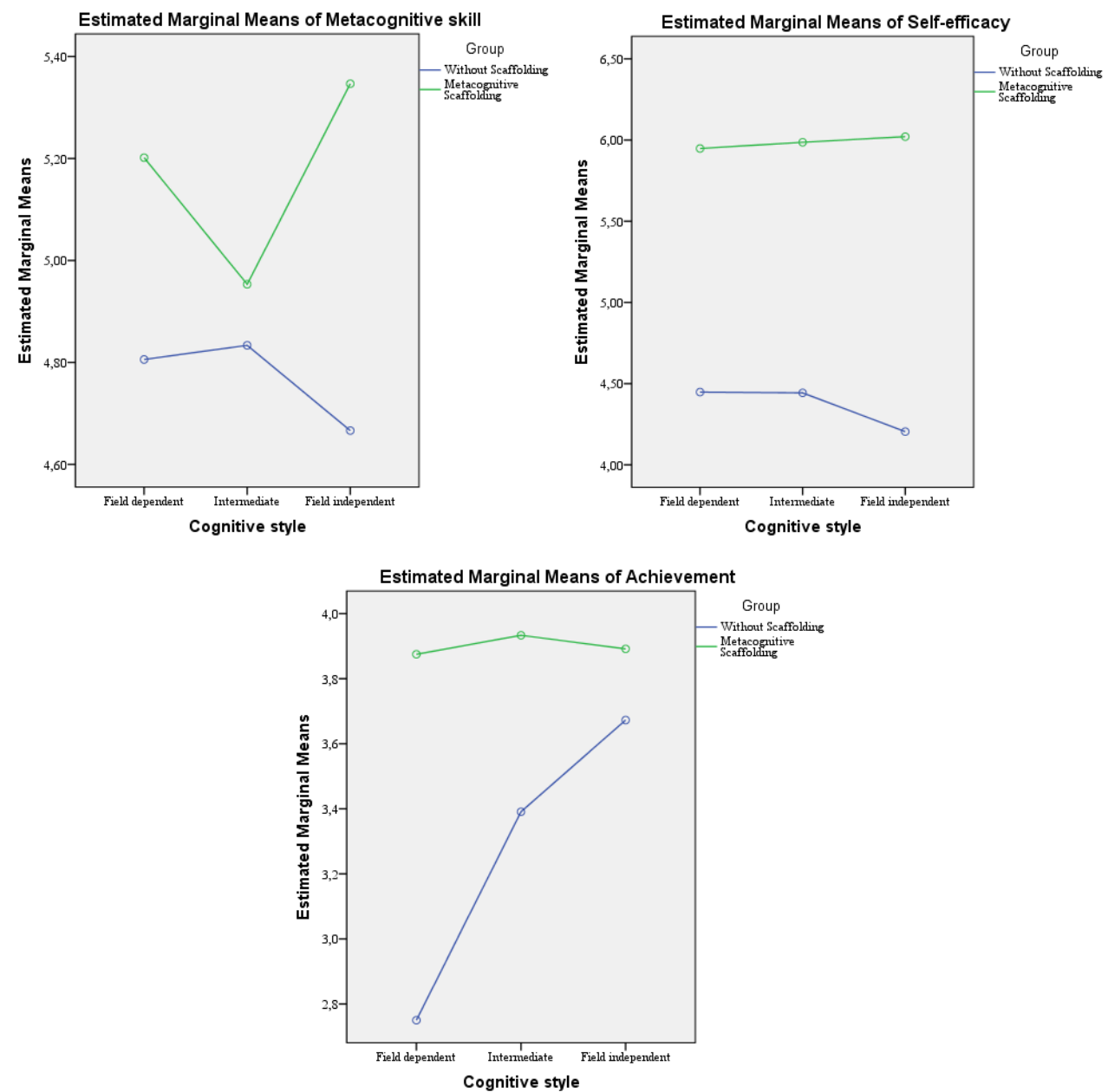

Fig. 4. Effect of cognitive style on metacognitive ability, academic self-efficacy, and learning achievement

Similarly, a significant main effect of the e-learning environment exists $(F(1,61)$ $=134.572, \mathrm{p}<=0.01, \eta 2=0.68)$ on academic self-efficacy. The students that worked with the scaffolding reported better levels of academic self-efficacy $(\mathrm{M}=5.98, \mathrm{SD}=0.51)$ compared to the students that did not use the scaffolding $(\mathrm{M}=4.36, \mathrm{SD}=0.59)$ (see Table 2) (see Fig. 4).

The analyses also show a significant main effect of the e-learning environment ( $F$ $(1,57)=10.072, p=0.002, \eta 2=0.150)$ on learning achievement. Students that worked with the scaffolding obtained better performances $(\mathrm{M}=3.89, \mathrm{SD}=0.96)$ compared to the students that did not use the scaffolding $(\mathrm{M}=3.25, \mathrm{SD}=1.09)$ (see Table 3) (see Fig. 4). Finally, cognitive style does not have a significant main effect on metacognitive ability ( $\mathrm{F}$ $(2,61)=2.49, \mathrm{p}=0.780, \eta 2=.008)$. Neither is there a significant effect on academic self- 
efficacy $(\mathrm{F}(2,61)=2.05, \mathrm{p}=0.815, \eta 2=.007)$ or learning achievement $(\mathrm{F}(2,61)=1.328$, $\mathrm{p}=0.272, \eta 2=.042$ ). (see Fig. 4).

Table 2

Academic self-efficacy results: Mean scores and standard deviations

\begin{tabular}{ccccc}
\hline e-Learning Environment & Cognitive Style & No. & M & SD \\
\hline With scaffolding & Field dependent & 12 & 6.04 & 0.31 \\
& Field intermediate & 9 & 5.96 & 0.48 \\
& Field independent & 12 & 5.91 & 0.64 \\
& Total & 33 & 5.98 & 0.51 \\
Without scaffolding & Field dependent & 12 & 4.44 & 0.64 \\
& Field intermediate & 11 & 4.44 & 0.43 \\
& Field independent & 11 & 4.20 & 0.70 \\
& Total & 34 & 4.36 & 0.59 \\
\hline
\end{tabular}

Table 3

Learning achievement results: Mean scores and standard deviations

\begin{tabular}{ccccc}
\hline e-Learning Environment & Cognitive Style & No. & M & SD \\
\hline With scaffolding & Field dependent & 12 & 3.87 & 0.95 \\
& Field intermediate & 9 & 3.93 & 0.81 \\
& Field independent & 12 & 3.89 & 1.15 \\
& Total & 33 & 3.89 & 0.96 \\
Without scaffolding & Field dependent & 12 & 2.75 & 1.23 \\
& Field intermediate & 11 & 3.39 & 1.00 \\
& Field independent & 11 & 3.67 & 0.84 \\
& Total & 34 & 3.25 & 1.09 \\
\hline
\end{tabular}

To precisely establish the effect of the metacognitive scaffolding on cognitive style in the FDI dimension and on learning achievement, a complementary Analysis of Variance (ANOVA) is performed to determine if significant differences exist between the learning achievements obtained by students.

The results show statistically significant differences in learning achievements ( $F$ $(2,31)=3.818, p=0.03, \eta 2=.19)$ between students with different cognitive styles in the FDI dimension that interact with the version of the e-learning environment without scaffolding. The multiple comparisons indicate that significant differences exist between FD and FI subjects $(\mathrm{t}(31)=2.559, \mathrm{p}=0.016)$, in favor of the FI subjects. Similarly, between FD and INT subjects $(\mathrm{t}(31)=2.204, \mathrm{p}=0.035)$, in favor of the INT subjects. No differences were reported between FI and INT novices $(\mathrm{t}(31)=0.410, \mathrm{p}=0.684)$. In the group of students that interacted with the version of the e-learning environment with the metacognitive scaffolding, no statistically significant effect was reported on learning achievement $(\mathrm{F}(2,30)=0.009, \mathrm{p}=0.991, \eta 2=.001)$. In other words, the performances of the novices from the experimental group, with different cognitive styles in the FDI dimension, are equivalent. 


\section{Conclusion}

The study's results evidence that the use of the metacognitive scaffolding has a significant and positive effect on students' learning achievement, metacognitive ability, and academic self-efficacy. On the other hand, it is possible to establish that the scaffolding incorporated in the e-learning environment equitably favors the performance of students with different cognitive styles in the FDI dimension.

Regarding the first research question, the study's analyses indicate that students interacting with metacognitive scaffolding present better learning achievements than classmates that did not interact with the scaffolding. It is possible to establish that each one of the stages of the metacognitive scaffolding favors monitoring and control processes insofar as the metacognitive scaffolding suggests to the novice establishing a learning goal and planning a series of activities as a function of that goal. Subsequently, while executing the study plan, the environment helps the novice monitor their learning process through metacognitive activators and provides an evaluation module to evaluate their actual learning state, adjust their strategy if needed, and present the final evaluation in each lesson unit when they feel prepared to do so. These activities likely help the novice recognize themselves as an information processor and positively favor their selfefficacy perception when approaching learning processes in e-learning environments.

The objective of the self-evaluations in the e-learning environment is to stimulate constant monitoring and reflection on the content learned. Thus, students reflect about the topics that they do not grasp and what they still need to learn as a function of achieving the proposed goal. In this order of ideas, the scaffolding is a means for the novice to be an active participant in their own learning process and favors them realizing the responsibility they have to their own learning process. Hence, the use of scaffolding allows the student to make decisions on -what to do- and -how to do it. These findings constitute empirical evidence in this research field and support the results of previous research, where learning mathematics in computational scenarios that implement scaffolding for metacognitive training favors learning achievement (Kramarski \& Gutman, 2006; Kramarski \& Mizrachi, 2006).

Similarly, the scaffolding favors the positive evaluation of academic self-efficacy in students and in this regard, the study shows interesting evidence. It is possible to assert that the fact of stimulating reflection on the state of their own knowledge and having the opportunity of adjusting the goals as a function of their individual differences, as well as monitoring their knowledge through self-evaluations, leads the student to see themselves as a person capable of achieving their own goals at their own learning pace, situation that leads them to believe in themselves and in their own abilities. This type of aid probably triggers questions like: Am I reaching the learning goal, was the chosen learning strategy the most appropriate, do I understand the studied concepts clearly, do the learning results indicate that I must review the content, was the study time I employed sufficient, do the learning results indicate that I must try harder, among other metacognitive questions that empower the novice in their own process leading them to positively value their efficacy to autonomously learn mathematical content in b-learning scenarios.

Although these results are inconclusive, it is important to continue developing studies that research in-depth the relationships that can derive from the use of metacognitive scaffolding to favor students' motivation toward learning when interacting with Web-based learning environments and improving learning achievement (Moos, 2014; Moos \& Azevedo, 2008, 2009). 
Regarding the second research question, the results validate the effectiveness of metacognitive scaffolding on the learning achievement of students with different cognitive styles in the FDI dimension in the context of mathematics. It was possible to establish that field independent, intermediate, and dependent students reach equivalent lessons when learning mathematical content through a Web environment that incorporates, within its structure, a metacognitive scaffolding. Similarly, it is possible to evidence that the FD students are favored by the presence of the scaffolding. This situation likely translates into greater effort and persistence in the achievement of the established learning goals to obtain the desired learning achievement.

These results are interesting insofar as they contribute empirical evidence of the effect of this type of scaffolding in favor of FD students. It is likely that the metacognitive scaffolding designed for the present study motivated the field dependent students to use it; thus, making it possible for their academic performance to improve. These results concur with the work of López-Vargas, Hederich-Martinez, \& CamargoUribe (2012) regarding the use of scaffolding to self-regulate learning in computational scenarios and improve learning achievement, while respecting students' individual differences.

It is possible to establish that the presence of the scaffolding directs students' attention to monitor and control their learning. Specifically, this didactic aid drives novices to develop the activities in an organized fashion and to employ more efficient strategies considering their stylistic characteristics. In this sense, metacognitive awareness positively affects the novice's perception of believing in themselves and of being able to perform the tasks in the direct absence of a social aid. This finding is promising in supporting FD students, given their stylistic characteristics and to the extent that they require greater social support and assistance when learning in computational environments; characteristic which would be significantly reduced with the use of metacognitive scaffolding.

Finally, it is possible to evidence that Web-based environments that implement metacognitive-type scaffolding within their structure improve academic performance, while respecting individual differences. Thus, learning is more equitable and flexible when supporting FD students, who are favored by the support of metacognitive scaffolding (Hederich-Martinez \& Camargo-Uribe, 2015; Hederich-Martinez et al., 2016; López-Vargas et al., 2017). The use of this type of scaffolding make it possible for the student to be capable of monitoring and regulating their own learning process in computational environments without social aid. Similarly, this type of scaffolding can favor personal efficacy to autonomously develop learning tasks. Although the study's results are not conclusive, a prominent future is foreseeable for the development of research on the use of scaffolding that respect individual differences and equitably favor academic performance.

\section{Limitations and recommendations}

Some limitations that were present when developing the research include the sample size, since a greater number of participants would have allowed a broader generalization of this study's findings. Similarly, the subjectivity of students' answers is a limiting factor of self-reporting questionnaires, as is the case of the instrument that was used to measure the metacognitive ability and academic self-efficacy. It would be convenient to use other indicators that allow evidencing these variables in a more objective manner. 
For future studies, it is recommended that the scaffolding can disappear in time. The scaffolding that was used was fixed, which forces all students to use it independently of their learning needs. It is likely that a scaffolding that adjusts and disappears, according to students' differential learning needs would be more effective and equitable as a function of the desired learning achievements.

\section{ORCID}

Nilson Valencia-Vallejo (iD https://orcid.org/0000-0002-5868-1350

Omar López-Vargas (iD https://orcid.org/0000-0003-2298-6854

Luis Sanabria-Rodríguez (iD https://orcid.org/0000-0001-7042-1714

\section{References}

Alexander, E., Bresciani, S., \& Eppler, M. (2015). Knowledge scaffolding visualizations: A guiding framework. Knowledge Management and E-Learning, 7(2), 179-198.

Alomyan, H. (2004). Individual differences: Implications for web-based learning design. International Education Journal, 4(4), 188-196.

Angeli, C., Valanides, N., \& Kirschner, P. (2009). Field dependence-independence and instructional-design effects on learners' performance with a computer-modeling tool. Computers in Human Behavior, 25(6), 1355-1366.

Archer, L. K. (2003). The interactive effects of field dependence-independence and instructional aids on student achievement in web-based instructional systems. Doctoral thesis, University of Pittsburgh, USA.

Azevedo, R. (2005). Using hypermedia as a metacognitive tool for enhancing student learning? The role of self-regulated learning. Educational Psychologist, 40(4), 199_ 209.

Azevedo, R., \& Hadwin, A. F. (2005). Scaffolding self-regulated learning and metacognition - Implications for the design of computer-based scaffolds. Instructional Science, 33(5/6), 367-379.

Brown, A. L. (1987). Metacognition, executive control, self-regulation, and other more mysterious mechanisms. In F. E. Weinert \& R. H. Kluwe (Eds.), Metacognition, Motivation, and Understanding (pp. 65-116). Hillsdale, NJ: Lawrence Erlbaum.

Chen, H. R., \& Tseng, H. F. (2012). Factors that influence acceptance of web-based elearning systems for the in-service education of junior high school teachers in Taiwan. Evaluation and Program Planning, 35(3), 398-406.

Chen, S. Y., \& Macredie, R. D. (2002). Cognitive styles and hypermedia navigation: Development of a learning model. Journal of the American Society for Information Science and Technology, 53(1), 3-15.

DeTure, M. (2004). Cognitive style and self-efficacy: Predicting student success in online distance education. American Journal of Distance Education, 18(1), 21-38.

Flavell, J. H. (1976). Metacognitive aspects of problem solving. In L. B. Resnick (Ed.), The Nature of Intelligence (pp. 231-235). Pittsburgh, PA: Lawrence Erlbaum Associates.

Graesser, A. C., McNamara, D. S., \& VanLehn, K. (2005). Scaffolding deep comprehension strategies through Point\&Query, AutoTutor, and iSTART. Educational Psychologist, 40(4), 225-234.

Greene, J. A., Moos, D. C., Azevedo, R., \& Winters, F. I. (2008). Exploring differences between gifted and grade-level students' use of self-regulatory learning processes 
with hypermedia. Computers \& Education, 50(3), 1069-1083.

Handal, B., \& Herrington, A. (2004). On being dependent or independent in computer based learning environments. e-Journal of Instructional Science and Technology, 7(2). Retrieved from https://files.eric.ed.gov/fulltext/EJ850352.pdf

Hederich-Martinez, C., \& Camargo-Uribe, A. (2015). Cognitive style and educational performance. The case of public schools in Bogotá, Colombia. Educational Psychology, 36(4), 719-737. doi:10.1080/01443410.2015.1091916.

Hederich-Martinez, C., López-Vargas, O., \& Camargo-Uribe, A. (2016). Effects of the use of a flexible metacognitive scaffolding on self-regulated learning during virtual education. International Journal of Technology Enhanced Learning, 8(3/4), 199-216.

Hsu, P. S., \& Dwyer, F. (2004). Effect of level of adjunct questions on achievement of field independent/field dependent learners. International Journal of Instructional Media, 31(1), 99-106.

Hsu, T. E., Frederick, F. J., \& Chung, M. L. (1994). Effects of learner cognitive styles and metacognitive tools on information acquisition paths and learning in hyperspace environments. Retrieved from https://files.eric.ed.gov/fulltext/ED373721.pdf

Huertas, A., López, O., \& Sanabria, L. (2017). Influence of a metacognitive scaffolding for information search in b-learning courses on learning achievement and its relationship with cognitive and learning style. Journal of Educational Computing Research, 55(2), 147-171.

Kazu, I. Y., \& Demirkol, M. (2014). Effect of blended learning environment model on high school students' academic achievement. Turkish Online Journal of Educational Technology, 13(1), 78-87.

Kim, M. C., \& Hannafin, M. J. (2011). Scaffolding problem solving in technologyenhanced learning environments (TELEs): Bridging research and theory with practice. Computers \& Education, 56(2), 403-417.

Kramarski, B., \& Gutman, M. (2006). How can self-regulated learning be supported in mathematical e-learning environments? Journal of Computer Assisted Learning, 22(1), 24-33.

Kramarski, B., \& Mizrachi, N. (2006). Online discussion and self-regulated learning: Effects of instructional methods on mathematical literacy. Journal of Educational Research, 99(4), 218-231.

Lajoie, S. P. (2005). Extending the scaffolding metaphor. Instructional Science, 33(5/6), 541-557.

Law, V., Ge, X., \& Eseryel, D. (2011). An investigation of the development of a reflective virtual learning community in an ill-structured domain of instructional design. Knowledge Management \& E-Learning, 3(4), 513-533.

Lehmann, T., Hähnlein, I., \& Ifenthaler, D. (2014). Cognitive, metacognitive and motivational perspectives on preflection in self-regulated online learning. Computers in Human Behavior, 32, 313-323.

López-Vargas, O., Hederich-Martinez, C., \& Camargo-Uribe, A. (2011). Estilo cognitivo y logro académico [Cognitive Style and Academic Achievement]. Educación y Educadores, 14(1), 67-82.

López-Vargas, O., Hederich-Martinez, C., \& Camargo-Uribe, A. (2012). Logro de aprendizaje en ambientes hipermediales: Andamiaje autorregulador y estilo cognitivo [Academic achievement in hypermedia environments, scaffolding self-regulated learning and cognitive style]. Revista Latinoamericana de Psicología, 44(2), 13-26.

López-Vargas, O., Ibáñez-Ibáñez, J., \& Racines-Prada, O. (2017). Students' metacognition and cognitive style and their effect on cognitive load and learning achievement. Educational Technology \& Society, 20(3), 145-157.

López-Vargas, O., \& Triana-Vera, S. (2013). Efecto de un activador computacional de 
autoeficacia sobre el logro de aprendizaje en estudiantes de diferente estilo cognitivo [Effect of a self-efficacy computational activator on the learning achievement in students of different cognitive style]. Revista Colombiana de Educación, 64(1), 225244.

López-Vargas, O., \& Valencia-Vallejo, N. G. (2012). Diferencias individuales en el desarrollo de la autoeficacia y el logro académico: el efecto de un andamiaje computacional [Individual differences in the development of self-efficacy and academic achievement: the effect of a computational structure]. Acta Colombiana de Psicología, 15(2), 29-41.

Lu, J., Yu, C. S., \& Liu, C. (2003). Learning style, learning patterns, and learning performance in a WebCT-based MIS course. Information \& Management, 40(6), 497-507.

McNeill, K. L., Lizotte, D. J., Krajcik, J., \& Marx, R. W. (2006). Supporting students' construction of scientific explanations by fading scaffolds in instructional materials. Journal of the Learning Sciences, 15(2), 153-191.

Molenaar, I., van Boxtel, C. A. M., \& Sleegers, P. J. C. (2010). The effects of scaffolding metacognitive activities in small groups. Computers in Human Behavior, 26(6), $1727-1738$.

Moos, D. C. (2014). Setting the stage for the metacognition during hypermedia learning: What motivation constructs matter? Computers \& Education, 70, 128-137.

Moos, D. C., \& Azevedo, R. (2008). Monitoring, planning, and self-efficacy during learning with hypermedia: The impact of conceptual scaffolds. Computers in Human Behavior, 24(4), 1686-1706.

Moos, D. C., \& Azevedo, R. (2009). Self-efficacy and prior domain knowledge: To what extent does monitoring mediate their relationship with hypermedia learning? Metacognition and Learning, 4(3), 197-216.

Nelson, T. O., \& Narens, L. (1990). Metamemory: A theoretical framework and new findings. The Psychology of Learning and Motivation, 26, 125-173.

Palmquist, R. A., \& Kim, K. S. (2000). Cognitive style and on-line database search experience as predictors of web search performance. Journal of the Association for Information Science and Technology, 51(6), 558-566.

Pintrich, P. R., Smith, D., Garcia, T., \& McKeachie, W. (1991). A manual for the use of the motivated strategies for learning questionnaire (MSLQ). Ann Arbor, MI: National Center for Research to Improve Postsecondary Teaching and Learning. The University of Michigan, USA.

Quintana, C., Zhang, M., \& Krajcik, J. (2005). A framework for supporting metacognitive aspects of online inquiry through software-based scaffolding. Educational Psychologist, 40(4), 235-244.

Sawa, H. (1966). Analytic thinking and synthetic thinking. Bulletin of Faculty of Education (Nagasaki University), 13, 1-16.

Schmidt, A. M., \& Ford, J. K. (2003). Learning within a learner control training environment: The interactive effects of goal orientation and metacognitive instruction on learning outcomes. Personnel Psychology, 56(2), 405-429.

Schraw, G., \& Moshman, D. (1995). Metacognitive theories. Educational Psychology Review, 7(4), 351-371.

Schunk, D. H. (1989). Self-efficacy and achievement behaviors. Educational Psychology Review, 1(3), 173-208.

Schunk, D. H., \& Zimmerman, B. J. (2007). Influencing children's self-efficacy and selfregulation of reading and writing through modeling. Reading \& Writing Quarterly, 23(1), 7-25.

Shih, C. C., \& Gamon, J. A. (2002). Relationships among learning strategies, patterns, styles, and achievement in web-based courses. Journal of Agricultural Education, 
43(4), 1-11.

Tsai, C. C., Chuang, S. C., Liang, J. C., \& Tsai, M. J. (2011). Self-efficacy in internetbased learning environments: A literature review. Educational Technology \& Society, 14(4), 222-240.

Usher, E. L., \& Pajares, F. (2009). Sources of self-efficacy in mathematics: A validation study. Contemporary Educational Psychology, 34(1), 89-101.

Valencia-Vallejo, N., López-Vargas, O., \& Sanabria-Rodríguez, L. (2016). Self-efficacy in computer-based learning environments: A bibliometric analysis. Psychology, 7(14), 1839-1857.

Valencia-Vallejo, N., López-Vargas, O., \& Sanabria-Rodríguez, L. (2018). Effect of a motivational scaffolding on e-learning environments: self-efficacy, learning achievement, and cognitive style. Journal Educators Online, 15(1): 5.

Vygotsky, L. S. (1978). Mind in society: The development of higher mental process. Cambridge, MA: Harvard University Press.

Wood, D., Bruner, J. S., \& Ross, G. (1976). The role of tutoring in problem solving. Journal of Child Psychology and Psychiatry, 17(2), 89-100.

Zhang, M., \& Quintana, C. (2012). Scaffolding strategies for supporting middle school students' online inquiry processes. Computers \& Education, 58(1), 181-196.

Zimmerman, B. J. (1995). Self-efficacy and educational development. In A. Bandura (Ed.), Self-efficacy in Changing Societies (pp. 202-231). New York, NY: Cambridge University Press. 